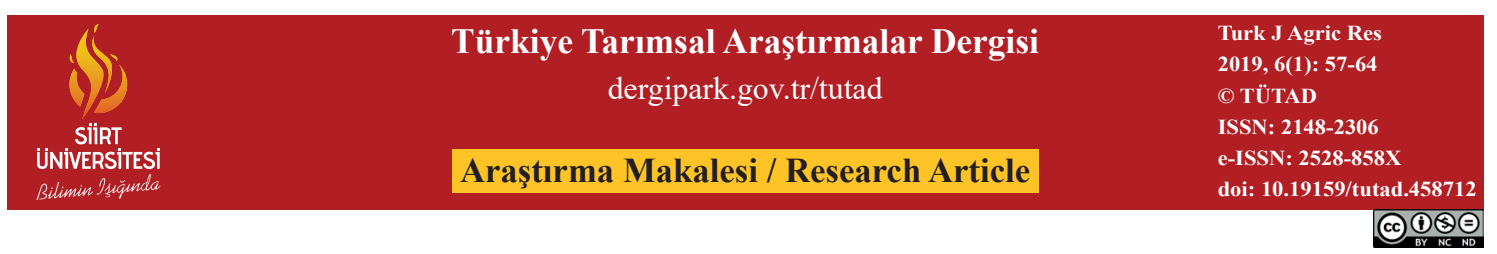

\title{
Farklı Elma Çeşitleri Üzerine Asılan Tuzakların Tropinota hirta (Poda, 1761) (Coleoptera: Cetoniidae'nın Yakalaması Üzerine Etkisi*
}

\author{
Bülent YAŞAR ${ }^{* *}$, Omar Ali DAHHAM DAHHAM \\ Isparta Uygulamalı Bilimler Üniversitesi, Tarım Bilimleri ve Teknolojileri Fakültesi, Bitki Koruma Bölümü, Isparta, TÜRKIYE
}

\begin{tabular}{ll}
\hline \multicolumn{1}{c}{ Gelis Tarihi/Received: 10.09 .2018} & Kabul Tarihi/Accepted: 22.02 .2019 \\
\hline ORCID ID (Yavar sirasma göre / by author order) & \\
\hline (1) orcid.org/0000-0002-2302-2267 (D) orcid.org/0000-0002-4068-3219 & \\
"Sorumlu Yazar/Corresponding Author: bulentyasar99@hotmail.com
\end{tabular}

*Sorumlu Yazar/Corresponding Author: bulentyasar99@hotmail.com

Öz: Bu çalışmada; 2017-2018 yıllarında, Isparta ilinde Red Chief, Williams Pride ve Braeburn elma çeşitlerinin çiçeklerinde beslenen Tropinota hirta'nın tuzaklarla yakalanmasına, çeşitlerin etkisi ile tuzak asılan ve asılmayan ağaçlardaki çiçeklerde zarar oranlarının karşılaş̧ırılması amaçlanmıştır. Araştırmada, denemeler beş tekerrürlü olarak gerçekleştirilmiştir. Çalışmada altında su bulunan açık mavi renkli huni tuzakları ve çekici olarak da trans-sinnamil alkol ve anetol 1:1 oranında kullanılmıştır. Sonuçta; hem 2017 hem de 2018 yıllarında tüm çeşitler için, tuzak asılmayan kontrollerdeki çiçek sayılarının, tuzak asılan ağaçlardakilerden daha fazla olduğu saptanmıştır. Bunun nedeninin, ergin böceklerin tuzaklardaki renk, su ve çekiciler ile ağaçlara doğru çekilmesi sonucunda tuzak asılan ağaçların çiçeklerinde daha fazla zarara yol açması olarak değerlendirilmiştir. $\mathrm{Bu}$ sonuçlar, tuzakların ağaçlardan daha uzağa asılarak erginlerin yakalanmasının daha uygun bir yöntem olacağını ortaya koymuştur. Çalışmada, 2017 yılında en fazla çiçek sayısına; Williams Pride, daha sonra Braeburn ve diğerlerine göre daha az miktarda Red Chief çeşidi sahip olmuştur. Benzer sonuçlar tuzak asılmayan ve sadece çiçekleri sayılan çeşitlerde de elde edilmiştir. Çalışmanın 2018 yılında ise bu sıralama değişerek en fazla çiçek sayısına Red Chief, daha sonra Braeburn ve en az çiçeğe Williams Pride sahip olmuştur. Bunun nedeninin o y1lın çiçek tomurcuğu farklılaşmasının gerçekleşmesi ya da bir önceki yıldaki iklim koşullarının etkili olduğu düşünülmektedir.

Anahtar Kelimeler: Cezbedici, Braeburn, Red Chief, Williams Pride, mavi huni

\section{The Effects of Traps Hanged on Different Apple Varieties on the Capture of Tropinota hirta (Poda, 1761) (Coleoptera: Cetoniidae)}

Abstract: The aim of this study was to capture the Tropinota hirta, fed in the flowers of the Red Chief, Williams Pride and Braeburn apple varieties with traps in Isparta province in 2017-2018, and to compare the damage rate and effect of varieties on trapped and untrapped trees. In the study, the experiments were carried out with five replications. In the study, light blue colored funnel traps with water and attractant (E) -cinnamyl alcohol and [(E) -anethol 1:1 ratio were used. As a result, for all varieties in both 2017 and 2018, it was determined that the number of flowers in the control trees was more than in the trapped ones. The reason for this is that the insects are attracted to the traps by the colors, water, and attractors on trees, and caused more damage to the flowers of trapped trees. These results show that traps can be hung farther from the trees, making catching adults more convenient. In the year of 2017, Williams Pride variety had the highest number of flowers, followed by Braeburn and the lowest number of flowers compared to others were obtained on Red Chief. Similar results were obtained in varieties where the trap was not hung and only the flowers were counted. In 2018, the ranking of the most flowers was changed by the Red Chief, and then by Braeburn, and by least by Williams Pride. This is thought to be due to the differentiation of the flower buds of that year or the climate conditions of the previous year.

Keywords: Attractant, Braeburn, Red Chief, Williams Pride, blue funnel

\footnotetext{
": Bu çalışma; Süleyman Demirel Üniversitesi, Fen Bilimleri Enstitüsü tarafından kabul edilen ikinci yazara ait "Farklı Elma Çeşitleri Üzerine Asılan Tuzakların Tropinota hirta (Coleoptera: Cetoniidae)'nın Yakalaması Üzerine Etkisi” isimli Yüksek Lisans Tez çalıșmasının bir böümünden üretilmiș olup; 11-13 Ekim 2018 tarihler arasında Antalya'da düzenlenen "6 ASM, International Congress of Agriculture and Environment" isimli kongrede sözlü bildiri olarak sunulmuş, adı geçen kongrenin bildiriler kitabında özet metni yayınlanmıştır.
} 


\section{Giriş}

Tropinota hirta; meyve ağaçları, süs bitkisi gibi birçok bitkinin çiçeklerinin üreme kısımlarında beslenmesi sonucu önemli zarar veren böcekler arasında yer almaktadır (Toth ve ark., 2003). Yapılan çalışmalarda T. hirta'nın özellikle; gül, kiraz, elma, kayısı, erik, şeftali, ahududu, böğürtlen ve baharda çiçek açan meyve ağaçlarına zarar verdikleri tespit edilmiştir (Kutinkova ve Andreev, 2004; Schmera ve ark., 2004; Vuts ve ark., 2010; Yaşar ve Uysal, 2013; Güvenç ve Yaşar, 2014). T. hirta bitkilerde sadece çiçek açma evresinde değil tomurcuk evrensinde de zararlı olmaktadır. Bu zararlı bitkilerde çiçeklerin taç yaprakları ile stamen ve stigma'larını çiğnemek suretiyle bitkileri kısırlaştırmaktadır (Vuts ve ark., 2010). T. hirta erginlerinin gündüzleri aktif, geceleri ise hareketsiz halde oldukları ve meyve ağaçlarının çiçeklerini, anter, polen ve pistil kısımlarını yiyerek meyve verim düşüşüne neden olduğunu belirlemişlerdir (Racksko ve ark., 2007).

$\mathrm{Bu}$ türün ergin ve larvaları kışı toprağın altında kış uykusunda geçirirler. Erginler bitkilerin çiçekleri ile beslenirken larvalar ölmüş bitki kalıntıları ve otların kökleri ile beslenmektedir. Bu zararlıya yıl içerisinde Nisan-Eylül dönemlerinde rastlanılmaktadır (Aydın, 2011). Larvaları bitkilerde herhangi bir zarara yol açmamaktadır (Vuts ve ark., 2010; Yaşar ve Sağdaş, 2014; Başpınar ve ark., 2017). Gündüzleri aktif olan T. hirta zararlısı gece boyunca toprağa gizlenmektedir. Böcek ilaçları kullanmak suretiyle T. hirta ile mücadele etmek oldukça zordur. Çünkü bitki çiçeklerinden beslenen bu zararlı ile mücadelede, bal arıları ve diğer faydalı canlılar etkilemesin diye çiçeklenme sırasında tarımsal ilaçlar kullanamamaktadır. Yapılan çalışmada mavi renkli tuzakların bu zararlı ile mücadelede başarı sağladığı görülmüştür (Schmera ve ark., 2004).

Türkiye'de, T. hirta'nın; Bursa, Çanakkale, Erzurum, Karaman, Isparta, İzmir, Malatya, Manisa, Mersin ve Tokat illerinde ahududu, elma, erik, kayısı ve kiraz gibi meyve ağaçlarının çiçeklerinde ekonomik olarak zarar yaptığ 1 bildirilmiştir (Kara, 1992; Tezcan ve Pehlivan, 2001; Öztürk ve Ulusoy, 2003; Kaya ve Kovanc1, 2004; Öztürk ve ark., 2004; Özcan, 2007; Özbek, 2008; Aydın, 2011; Sağdaş ve Yaşar, 2013; Yaşar ve Uysal, 2013; Yaşar ve ark., 2013; Gezer ve Özpinar, 2015).

T. hirta ile mücadelede kimyasal uygulamaların yapılamamasından dolayı genel olarak bu zararlıya karşı biyoteknik yöntemler uygulanmıştır. $\mathrm{Bu}$ çalışmalarda en uygun çekicilerin genelde trans-sinnamil alkol ve anetol karışımını 1:1 oranında kullanılmasının uygun olduğu, huni tuzaklarıyla bu türün erginlerinin yakalanmasında araştırıcılara göre değişen mavi renk tonlarının etkili olduğu, huni tipi tuzakların alt kısımlarına konan suyun da önemli olduğu bildirilmiştir. Ayrıca, kullanılan tuzakların asılma yükseklilerinin de bu türün erginlerini çekme de önemli olduğu rapor edilmiştir (Toth ve ark., 2003, 2009; Schmera ve ark., 2004; Vuts ve ark., 2010; Mitko ve ark., 2011; Sağdaş, 2011; Yaşar ve ark., 2013).

Bu çalışmada, aynı içerikte çekici madde içeren mavi renkli huni tuzaklarının farklı çeşitlerdeki elma ağaçlarına asılması sonucunda, T. hirta erginlerinin bu tuzaklara yönelme oranlarını saptamak amaçlanmıştır.

\section{Materyal ve Yöntem}

\subsection{Materyal}

Çalışmanın materyalini T. hirta erginlerini yakalamak için oluşturulan açık renkli mavi huni tipi tuzaklarının üzerine konulan falkon tüpler içindeki pamuk üzerine damlatılan trans-sinnamil alkol ve anetol içeren çekiciler oluşturmuştur.

\subsection{Yöntem}

\subsubsection{Arazi çalıșmaları}

Arazi çalışmaları; Isparta Süleyman Demirel Üniversitesi, Tarımsal Araştırma ve Uygulama Merkezi arazisindeki elma bahçelerinde gerçekleştirilmiştir.

Çalışmalar; bu bahçe içerisinde toplam 9 sıra ve 3 çeşit (Red Chief, Williams Pride ve Braeburn)'ten oluşan, 8-10 yaşındaki elma çeşitleri üzerinde yapılmıştır. Her çeşitten 5'er adet ağaç (tekerrür) işaretlenerek tuzaklar doğu yönünde bulunan $1.5 \mathrm{~m}$ yükseklikteki dallara asılmıştır. Tuzakların birbirlerinden uzaklıklarının 8 metre olmasına dikkat edilmiştir. Ayrıca bu tuzakların aralarına kontrol olarak birer ağaçtan 5 adet ağaç işaretlenerek belirlenmiştir. İşaretlenen tüm ağaçların sıra aralarına bakan dış yüzeylerinde toplam $6(3+3)$ adet dal belirlenerek; bunlar üzerinde uçtan itibaren $1 \mathrm{~m}$ uzunluğundaki alanda bulunan çiçek döneminde, çiçekler ve meyve döneminde de meyve sayımları yapılmıştır.

Cezbedici madde hazırlanırken etken maddeler (trans-sinnamil alkol ve anetol) 1:1 oranında karıştırılmıştır. Kullanılan tüm cezbediciler, sıvı emme kabiliyeti yüksek olan özel pamuklar üzerine mikro pipet yardımıyla her birinden $20 \mu \mathrm{l}$ olarak damlatılmıştır. Üzerine çekici damlatılan pamuklar 3 x $13 \mathrm{~cm}$ uzunluğundaki plastik falkon tüpler içerisine yerleştirilerek falkon tüplerin ağzı kapatılmıştır. Falkon tüplerin içerisindeki kokunun 
dışarıya çıkmasına olanak veren ve aynı zamanda içeriye yağmur girmesini de önleyecek şekilde falkon tüplerin etrafına yaklaşı 20 adet $0.3 \mathrm{~mm}$ çapında delikler açılmıştır. Bu tüpler kapak kısmının hemen altından karşılıklı delinerek içerisinden paslanmaz tel geçirilmiş ve hunilerin kenarlarına bağlanmıştır. Böylece çekicilere yaklaşan erginlerin bidon içerisinde bulunan suya yönelme isteklerinden dolayı buraya düşmelerinin sağlanması hedeflenmiştir.

Tuzaklarda kullanılan huniler ise açık mavi renge boyanmıştır. Hunilerin içlerine hazırlanan cezbediciler konularak huninin ince kısmına pet şişeler bağlanıp elma ağaçlarının dallarına iple sabitlenmek suretiyle asılmıştır (Şekil 1).

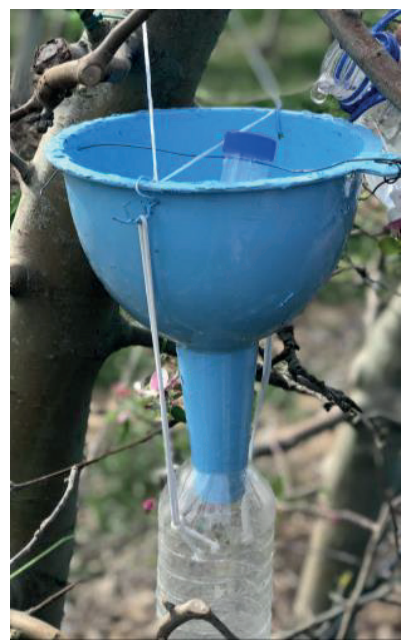

Şekil 1. Araştırmada kullanılan tuzakların genel görünümü

Tuzaklardaki mavi hunilerin altına 1 litrelik birer pet şişe konularak pet şişenin içerisi $1 / 3$ oranında su ile doldurulmuştur. $\mathrm{Bu}$ pet şişelerin üstten 1/3'lük kısmından böceklerin kaçamayacağ1 küçüklükte delikler açılarak, yağmur yağması halinde pet şişedeki fazla suyun tahliyesine imkân tanınmıştır. $\mathrm{Bu}$ tahliye giderleri ile yağmur yağması durumunda böceklerin tuzaklardan kaçmasının engellenmesi amaçlanmıştır.

Tuzakların araziye yerleştirilmesi elma bahçelerinde ağaçlar çiçek açmadan önce Nisan ayının başında gerçekleştirilmiştir. İlk $T$. hirta ergini görüldüğünde de cezbediciler tuzaklara konulmuştur. Yakalanan T. hirta sayımları elma ağaçlarının çiçekleri tamamen dökülünceye kadar haftada üç kez (pazartesi, çarşamba ve cuma) tüm tuzaklar kontrol edilerek yapılmıştır.

Çalışmada elde edilen verilerin karşılaştırılmasında çoklu karşılaştırma yöntemlerinden Tukey testi $(p<0.05)$, ikili karşılaştırmalarda ise t testi kullanılmıştır. Yapılan istatiksel analizlerde SPSS (Ver.22) programindan yararlanılmıştır (Anonymous, 2014).

\section{Bulgular ve Tartışma}

\section{1. İlk yıl (2017 yılı) sonuçları}

Çalışmada, 2017 yılındaki tüm elma çeşitleri bir arada incelendiğinde, her üç çeşitte yakalanan T. hirta sayısı ortalama hava sıcaklığı ile uyumlu olarak dalgalanmalar göstermiştir (Şekil 2). Ancak bunlar içinde Braeburn elma çeşidindeki tuzaklar diğerlerinden daha fazla ergin yakalamış ve istatistikî olarak aralarındaki fark önemli bulunmuştur $(\mathrm{p}<0.05) \quad$ (Tablo 1). $\mathrm{Bu}$ veriler ışı̆̆ında 2017 yılında $T$. hirta erginlerinin Braeburn elma çeşidinin çiçeklerini, denemedeki diğer çeşitlere göre daha fazla tercih ettiği söylenebilir. T. hirta'nın güneşli havalarda aktif olduğu ve havanın kapalı veya soğuk olması durumunda ise toprakta saklandığı bildirilmiştir

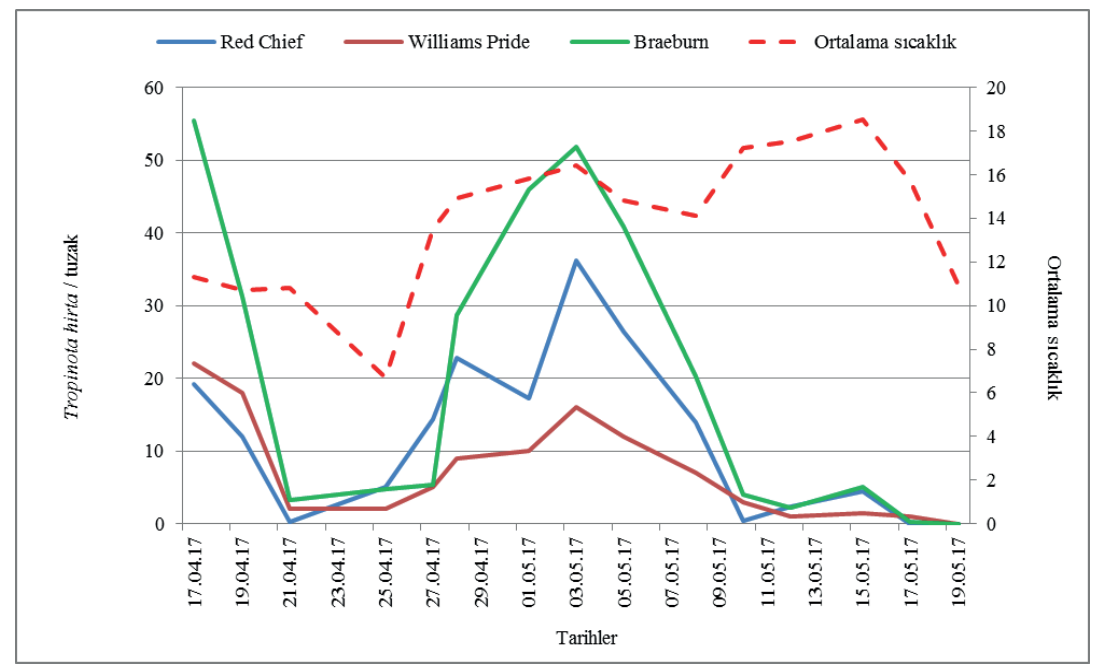

Şekil 2. İlk (2017) yılda tüm elma çeşitlerinde tuzaklarda yakalanan T. hirta sayıları 
Tablo 1. Her iki yılda yakalanan Tropinota hirta ve dallardaki çiçek sayıları (Ort $\pm \mathrm{SH})$

\begin{tabular}{lcccc}
\hline \multirow{2}{*}{ Sayımlar } & \multirow{2}{*}{ Y1llar } & \multicolumn{3}{c}{ Elma çeşitleri* $^{*}$} \\
\cline { 3 - 5 } & 2017 & Williams Pride & Braeburn & Red Chief \\
\hline \multirow{2}{*}{ Tuzaklardaki $T$. hirta } & 2018 & $5.40 \pm 1.86 \mathrm{c}$ & $19.92 \pm 5.3 \mathrm{a}$ & $11.67 \pm 2.89 \mathrm{~b}$ \\
& 2017 & $84.05 \pm 6.15 \mathrm{~b}$ & $8.15 \pm 1.85 \mathrm{a}$ & $6.4 \pm 1.25 \mathrm{ab}$ \\
\hline \multirow{2}{*}{ Kontroldeki çiçekler } & 2018 & $194.31 \pm 8.57 \mathrm{c}$ & $28.40 \pm 2.24 \mathrm{~b}$ & $17.30 \pm 1.26 \mathrm{c}$ \\
& 2017 & $28.96 \pm 2.18 \mathrm{a}$ & $23.92 \pm 15.2 \mathrm{~b}$ & $295.84 \pm 13.5 \mathrm{a}$ \\
\hline \multirow{2}{*}{ Tuzak asılan ağaçlardaki } & 2018 & $125.82 \pm 3.93 \mathrm{c}$ & $201.10 \pm 14.19 \mathrm{~b}$ & $251.4 \pm 11.16 \mathrm{a}$ \\
\hline
\end{tabular}

*: Aynı satırda aynı harfle gösterilen rakamlar arasındaki fark istatistikî olarak önemli değildir ( $<0.05$ ), Ort: Ortalama, SH: Standart sapma

(Böhm, 1950; Güvenç ve Yaşar, 2014). Şekil 2'de gösterildiği gibi 2017 yılında 17-25 Nisan tarihleri arasında ortalama sıcaklık değerlerinin düşmesi sonucu tüm elma çeşitlerindeki tuzaklarda yakalanan böcek sayılarında da azalma saptanmıştır.

Araştırmada, 2017 yılında tuzak asılan tüm elma çeşitlerindeki çiçek sayıları ve ortalama sıcaklık değerleri Şekil 3'te verilmiştir. Çalışmada, 2017 yılında tuzak asılan ve asılmayan tüm elma çeşitlerindeki en fazla çiçek sayısı Williams Pride elma çeşidinde saptanmıştır. Tuzak asılan ağaçlardaki çiçek sayıları karşılaştırıldığında, tuzaklarda yakalanan $T$. hirta sayılarında olduğu gibi Williams Pride elma çeşidinde diğerlerinden daha fazla olmuş ve istatistikî olarak aralarındaki fark önemli bulunmuştur $(\mathrm{p}<0.05) \quad$ (Tablo 1). Araştırmada, 2017 yılında tuzak asılmayan tüm elma çeşitlerindeki çiçek sayıları ve ortalama sıcaklık değerleri Şekil 4'te verilmiştir.

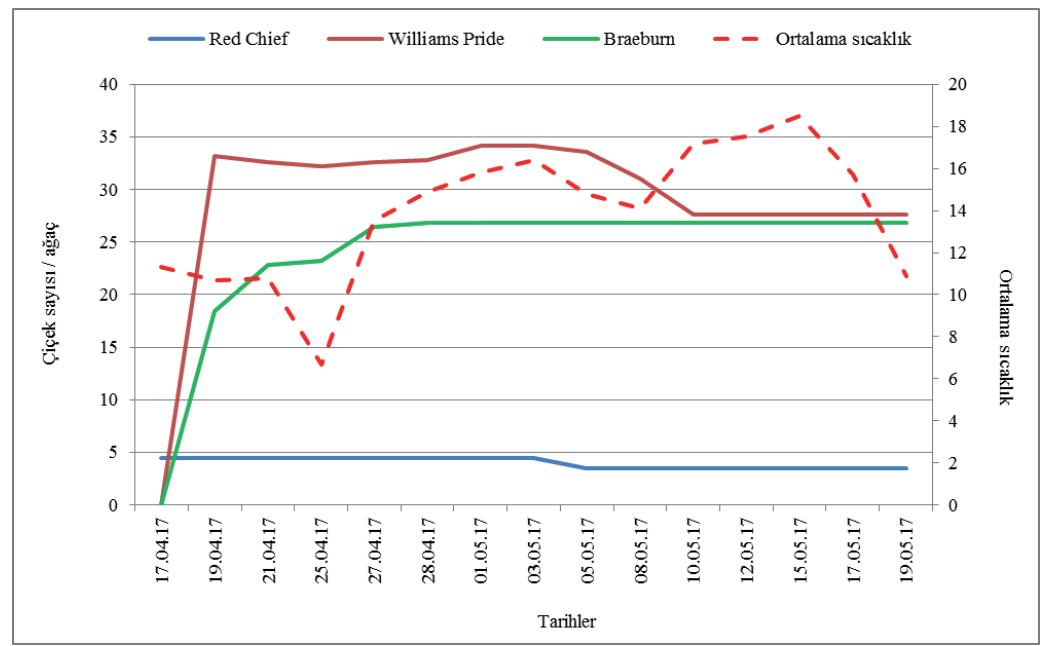

Şekil 3. İlk (2017) yılda tuzak asılan tüm elma çeşitlerindeki çiçek sayıları

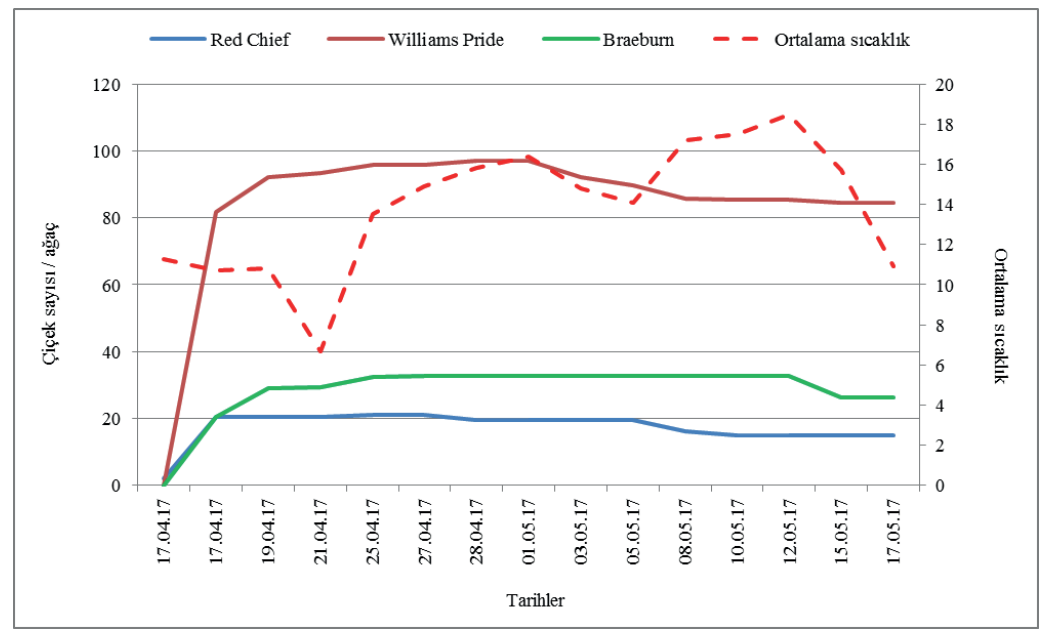

Şekil 4. İlk (2017) yılda tuzak asılmayan tüm elma çeşitlerindeki çiçek sayıları 
Tuzak asılmayan tüm elma çeşitlerindeki çiçek sayıları 2017 yılı için incelendiğinde, en fazla çiçek sayısı yine Williams Pride elma çeşidinde saptanmıştır. Tuzak asılmayan ağaçlardaki çiçek sayıları karşılaştırıldığında, tuzak asılana ağaçlardaki yakalanan T. hirta sayılarında olduğu gibi, Williams Pride elma çeşidinde diğerlerinden daha fazla olmuş ve istatistikî olarak aralarındaki fark önemli bulunmuştur $(\mathrm{p}<0.05)$ (Tablo 1).

Araştırmada, 2017 yılında tuzak asılan ve asılmayan tüm elma çeşitlerindeki çiçek sayıları içinde, Red Chief elma en az olduğu görülmüştür (Tablo 1). Bu farklılı̆̆ın, bu çeşidin çevre koşullarından diğerlerine göre daha fazla etkilenmesi sonucunda olduğu düşünülmektedir.

\section{2. İkinci yıl (2018 yılı) sonuçları}

Çalışmada, 2018 yılı tüm elma çeşitlerindeki tuzaklarda yakalanan $T$. hirta sayıları ve ortalama sıcaklık değerleri Şekil 5'te, tuzak asılan tüm elma çeșitlerindeki çiçek sayıları Şekil 6'da, tuzak asılmayan ağaçlardaki çiçek sayıları ise Şekil 7'de verilmiştir.

Her üç elma çeşidinde de ortalama sıcaklık ile uyumlu olarak tuzaklarda yakalanan $T$. hirta sayısında dalgalanmalar göstermiştir. Ancak bunlar içinde Braeburn elma çeşidi üzerine asılan tuzaklar diğerlerinden daha fazla $T$. hirta yakalamış ve Williams Pride elma çeşidi ile arasındaki fark istatistikî olarak önemli bulunmuştur $(\mathrm{p}<0.05) \quad$ (Tablo 1). $\mathrm{Bu}$ veriler ışı̆̆ında 2018 yılında T. hirta erginlerinin Braeburn ve Red Chief elma çeşitlerinin çiçeklerini daha fazla tercih ettiği söylenebilir.

Yaşar ve Uysal (2013), Isparta'da erik ve armut ağaçlarının çiçeklerinde zarar yapan $T$. hirta erginlerinin armut bahçelerindeki, Sağdaş (2011) ise Afyonkarahisar ili Sultandağı ilçesinde kiraz ve elma ağaçlarının çiçeklerinde zarar yapan $T$. hirta erginlerinin kiraz bahçelerindeki tuzaklarda daha

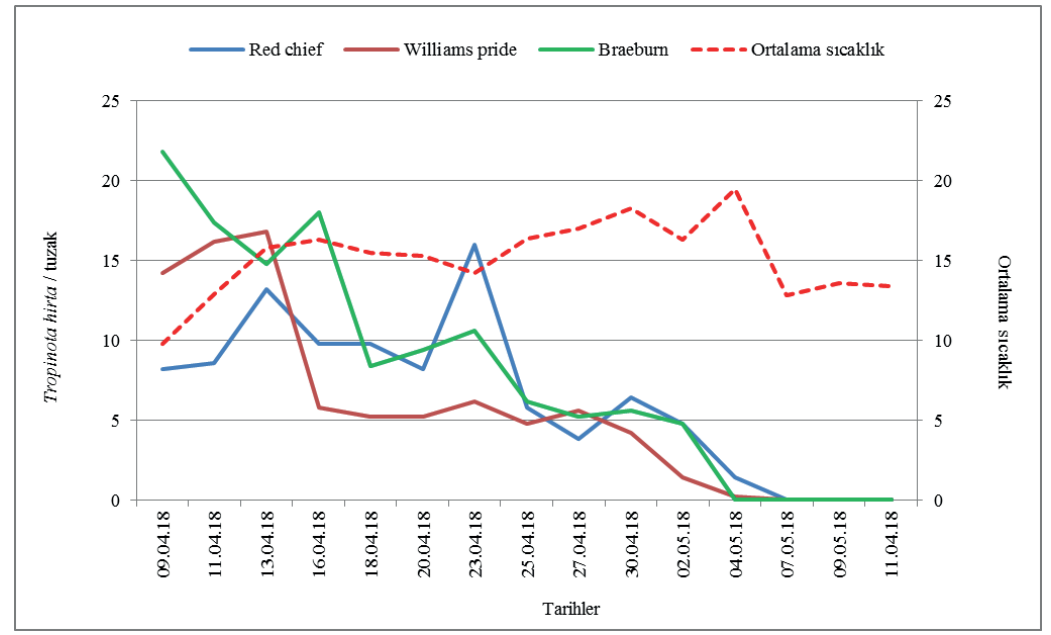

Şekil 5. İkinci (2018) yılda tüm elma çeşitlerindeki tuzaklarda yakalanan T. hirta sayıları

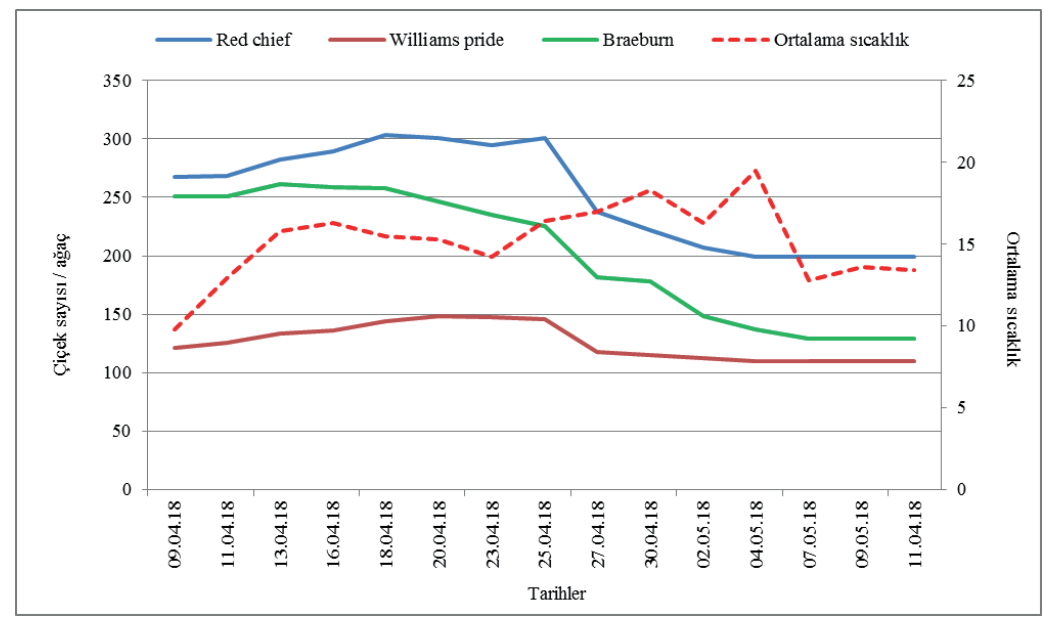

Şekil 6. İkinci (2018) yılda tuzak asılan tüm elma çeşitlerindeki çiçek sayıları 


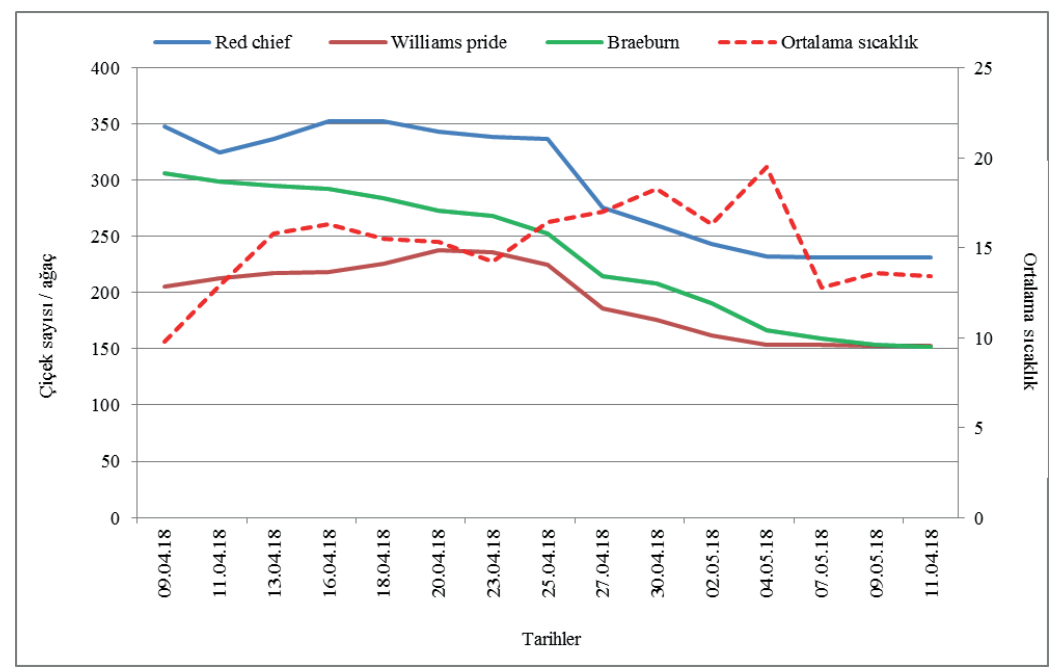

Şekil 7. İkinci (2018) yılda tuzak asılmayan tüm elma çeşitlerindeki çiçek sayıları

fazla yakalandıklarını bildirmişlerdir. Gezer ve Özpınar (2015), T. hirta ile ilgili 2013-2014 yıllarında yaptıkları bir çalışmada, şeftali ağaçlarında en fazla ergin bireyin sırasıyla şeftali, kiraz ve elma ağaçlarında yakalandığını bildirmişlerdir. Benzer şekilde Uysal (2011), armut ve eriklerde; Sağdaş (2011), kiraz ve elmalarda yaptıkları çalışmalarda yakalanan $T$. hirta erginlerinin bitki türlerinin farklı olmasından dolayı değiştiğini bildirmişlerdir.

$\mathrm{Bu}$ verilere göre, farklı bitkiler üzerinde kurulan tuzaklarda yakalanan T. hirta sayılarının, çalışmamızda aynı bitki türünün değişik çeşitlerinde de farklı olabileceğini göstermektedir. $\mathrm{Bu}$ farklılığın, çiçeklerin renk ve koku gibi böcekleri çeken özelliklerden kaynaklandığı düşünülmektedir.

Araştırmada, 2018 y1lında hem tuzak asılan hem de kontrollerdeki (tuzak asılmayan) tüm elma çeşitlerindeki çiçek sayıları incelendiğinde en fazla çiçek sayısı Red Chief elma çeşidinde saptanmıştır. Tuzak asılan ve kontrollerdeki (tuzak asılmayan) ağaçlardaki çiçek sayıları karşılaştırıldığında, Red Chief elma çeşidinde diğerlerinden daha fazla olmuş ve istatistikî olarak aralarındaki fark önemli bulunmuştur $(\mathrm{p}<0.05)$ (Tablo 1). İklim koşullarının uygun olması göz önünde bulundurularak, 2018 yılında çeşitler arasındaki çiçek sayılarının farklı olmasının o çeşitlerin özelliğinden kaynaklandığını söylemek mümkündür.

\section{3. İki yıllık (2017-2018 yılları) bulguların karşılaștırılması}

Çalışmada, 2017-2018 yıllarındaki tuzaklarda yakalanan T. hirta sayıları Tablo 2'de verilmiştir. Tüm sayımlarda 2018 yılında tuzaklarda yakalanan T. hirta sayıları 2017 yılına göre daha az olmuştur.
Yapılan istatistikî analizler sonucunda da yıllara göre tuzaklarda yakalanan $T$. hirta sayıları arasındaki fark istatistikî olarak önemli bulunmuştur $(\mathrm{p}<0.05)$.

Tropinota hirta sayılarının 2017 y1lında fazla olmasının nedeni, daha önce de belirtildiği gibi elma ağaçlarının çiçeklenme dönemindeki iklim koşullarıyla ilişkilidir. Bunun nedeni olarak 2018 yılında çiçeklenme döneminde havaların 2017 yılına göre daha bulutlu ve yağmurlu olmasından dolayı $T$. hirta erginlerinin daha az aktif olmalarından kaynaklandığı düşünülmektedir. $T$. hirta erginlerinin güneşli ve yağmursuz havalarda aktif olduğu ve çiçeklerde beslendiği bilinmektedir (Gezer ve Özpınar, 2015). Heath ve ark. (2007), çekicilerin yağmurlu havalarda bazı böcekleri çekmede daha az başarılı olduğunu bildirmektedir.

Tablo 2. Y1llara göre tuzaklarda yakalanan $T$. hirta sayıları

\begin{tabular}{|c|c|c|c|c|c|}
\hline $\begin{array}{l}\text { Elma } \\
\text { çeşitleri }\end{array}$ & Y1l & $\begin{array}{c}\text { Ortalama } \\
( \pm \text { SH })^{*}\end{array}$ & $\mathrm{t}$ & SD & $\mathrm{P}$ \\
\hline \multirow{2}{*}{ Red Chief } & 2017 & $11.67 \pm 2.89$ & \multirow{2}{*}{1.864} & \multirow{2}{*}{14} & \multirow{2}{*}{0.083} \\
\hline & 2018 & $6.40 \pm 1.25$ & & & \\
\hline \multirow{2}{*}{ Braeburn } & 2017 & $19.92 \pm 5.30$ & \multirow{2}{*}{2.470} & \multirow[t]{2}{*}{14} & \multirow{2}{*}{0.027} \\
\hline & 2018 & $8.15 \pm 1.85$ & & & \\
\hline Willims & 2017 & $7.41 \pm 1.86$ & \multirow{2}{*}{1.094} & \multirow{2}{*}{14} & \multirow{2}{*}{0.292} \\
\hline Pride & 2018 & $5.72 \pm 1.47$ & & & \\
\hline
\end{tabular}

${ }^{*}:$ Paired t-test $\mathrm{p} \leq 0.05$

Tropinota hirta sayılarında olduğu gibi, 2018 yılında hem tuzaklardaki hem de kontrol ağaçlarındaki çiçek sayıları 2017 yılına göre daha fazla olmuştur. Yapılan istatistikî analizler sonucunda da yıllara göre çiçek sayılarının arasındaki fark istatistikî olarak önemli bulunmuştur $(\mathrm{p}<0.05)$ (Tablo 3). Bunun nedeninin, daha önce de belirtildiği gibi yine ya o yılın çiçek 
Tablo 3. Yı1 ve çeşitlere göre ağaçlardaki çiçek sayıları

\begin{tabular}{|c|c|c|c|c|c|c|c|c|c|}
\hline \multirow{2}{*}{$\begin{array}{l}\text { Elma } \\
\text { çeşitleri }\end{array}$} & \multirow[b]{2}{*}{ Y11 } & \multicolumn{4}{|c|}{ Tuzak asılan ağaçlardaki çiçek sayıları } & \multicolumn{4}{|c|}{ Kontrollerdeki çiçek sayıları } \\
\hline & & $\begin{array}{c}\text { Ortalama } \\
( \pm \mathrm{SH})^{*}\end{array}$ & $\mathrm{t}$ & SD & $\mathrm{P}$ & $\begin{array}{l}\text { Ortalama } \\
( \pm \mathrm{SH})^{*}\end{array}$ & $\mathrm{t}$ & SD & $\mathrm{P}$ \\
\hline Red Chief & $\begin{array}{l}2017 \\
2018\end{array}$ & $\begin{array}{c}4.03 \pm 0.13 \\
269.52 \pm 12.03\end{array}$ & -22.31 & 14 & 0.000 & $\begin{array}{c}17.30 \pm 1.26 \\
295.84 \pm 13.50\end{array}$ & -20.93 & 14 & 0.000 \\
\hline Braeburn & $\begin{array}{l}2017 \\
2018 \\
\end{array}$ & $\begin{array}{c}23.92 \pm 1.82 \\
201.11 \pm 14.19\end{array}$ & -11.79 & 14 & 0.000 & $\begin{array}{c}29.28 \pm 2.26 \\
234.29 \pm 15.20\end{array}$ & -12.46 & 14 & 0.000 \\
\hline $\begin{array}{l}\text { Willims } \\
\text { Pride }\end{array}$ & $\begin{array}{l}2017 \\
2018\end{array}$ & $\begin{array}{c}28.96 \pm 2.18 \\
125.83 \pm 3.94\end{array}$ & -25.51 & 14 & 0.000 & $\begin{array}{c}84.05 \pm 6.15 \\
173.31 \pm 7.88\end{array}$ & -9.24 & 14 & 0.000 \\
\hline
\end{tabular}

*: Paired t-test $\mathrm{p} \leq 0.05, \mathrm{SD}$ : Serbestlik derecesi

tomurcuğu farklılaşmasının gerçekleşmesi ya da bir önceki yıldaki iklim koşullarının etkili olduğu düşünülmektedir.

\section{Sonuçlar}

$\mathrm{Bu}$ çalışma, 2017-2018 yıllarında Braeburn, Williams Pride ve Red Chief elma çeşitlerinin çiçeklerini yiyerek zarar yapan $T$. hirta erginlerinin huni tipi tuzaklarla yakalanması ve bu ağaçlardaki dökülen çiçek gözlerinin sayıları arasındaki ilişki ortaya konulmaya çalışılmıştır.

Her iki yılda yapılan çalışmalar sonucunda tüm çeşitler için, tuzak asılmayan ağaçlardaki çiçek sayılarının, tuzak asılanlara göre daha fazla olduğu saptanmıştır. Bunun nedeninin, T. hirta erginlerinin tuzaklardaki renk, suyun varlığ 1 ve çekici etkileri ile ağaçlara doğru çekilmesiyle bu ağaçların çiçeklerinin daha fazla dökülmesine yol açtığı sonucuna varılmıştır.

İlk yılda (2017) en fazla dökülmeyen çiçek sayısı Williams Pride, 2018 yılında Red Chief çeşidi olmuştur. Benzer sonuçlar tuzak asılmayan çeşitlerde de saptanmıştır.

Tüm çeşitlerdeki tuzaklarda yakalanan ergin sayıları, 2018 yılında daha az olmuştur. Bunun nedeninin, bu yılda havaların yağışlı ve kapalı olması sonucu ergin böceklerin daha az aktif olmasından kaynaklandığı düşünülmektedir.

Sonuç olarak; T. hirta'nın farklı elma çeşitlerine yönelme nedeninin, o çeşide ait renk ve özellikle koku ile ilgili olduğu sonucuna varılmıştır. Ancak, tuzakların T. hirta erginlerini çekmesine karşılık, bunların o ağaçtaki çiçeklerde de beslenerek zarar yaptığı ortaya konulmuştur. Ayrıca ortalama hava sıcaklığının düşük olması durumunda, hem kalan çiçek sayısının azaldığı hem de böceklerin tuzaklara gelmediği saptanmıştır. Bundan sonra yapılacak çalışmalarda, tuzakların ağaçlardan uzağa asılarak $T$. hirta erginlerinin yakalanması üzerine etkisinin araştırılmasının, bu konunun aydınlatılmasına katkı sağlayacağı düşüncesindeyiz.

\section{Teșekkür}

$\mathrm{Bu}$ çalışma; Süleyman Demirel Üniversitesi, Bilimsel Araştırma Projeleri Koordinasyon Birimi tarafindan "FYL-2018-5729" No'lu proje ile desteklenmiştir.

\section{Kaynaklar}

Anonymous, 2014. Statistical Program Social Sciences (Ver: 22.0). (http://www.spss.co.in/spssstatistics. aspx\#), (Erişim tarihi: 22.04.2018).

Aydın, G., 2011. Plant phenology-related shifts in color preferences of Epicometis (Tropinota) hirta (Coleoptera: Scarabaeidae: Cetoniinae) adults-key to effective population monitoring and suppression. Florida Entomologist, 94(4): 832-838.

Baspınar, H., Doll, D., Rijal, J., 2017. Pest Management in Organic Almond. V. Vacante and S. Kreiter (Eds.), Handbook of Pest Management in Organic Farming, CABI, Boston, pp. 328-347.

Böhm, H., 1950. Observations on the occurrence of Tropinota hirta injuring fruit blossom in Austria. Journal Pflanzenschutzberichte, 5(3-4): 241-257.

Gezer, B., Özpınar, A., 2015. Çanakkale ilinde şeftali, elma, kiraz ve kayss1larda Tropinota hirta (Poda) (Coleoptera: Cetoniidae) ergin yoğunluğunu belirlemede farklı tuzakların değerlendirilmesi. Çanakkale Onsekiz Mart Üniversitesi Ziraat Fakültesi Dergisi, 3(2): 27-34.

Güvenç, C., Yaşar, B., 2014. Mavi renkli huni tuzaklarda kullanılan farklı cezbedicilerin kiraz çiçeklerinde beslenen Tropinota hirta (Poda) (Coleoptera: Scarabaeidae) erginlerinin yakalanması üzerine etkisi. Süleyman Demirel Üniversitesi Fen Bilimleri Enstitüsü Dergisi, 18(3): 97-104.

Heath, R., Epsky, N., Kendra, P., Mangan, R., 2007. Introductory paper: Fruit fly trapping and control past, present and future. Development of improved attractants and their integration into fruit fly sit management programmes. Proceedings of a Final Research Coordination Meeting Organized by the Joint FAO/IAEA Programme of Nuclear Techniques in Food and Agriculture and Held in Vienna, 5-7 May, pp. 7-10.

Kara, K., 1992. Tropinota hirta (Poda) (Coleoptera: Scarabaeidae'nin Tokat ve çevresindeki 
konukçuları, yayılışı, zarar düzeyi, bazı biyolojik özellikleri ve mücadele imkânları üzerinde araştırmalar. Yüksek lisans tezi, Cumhuriyet Üniversitesi, Fen Bilimleri Enstitüsü, Tokat.

Kaya, M., Kovanc1, B., 2004. Bursa'da ahududu alanlarında saptanan Coleoptera türleri. Çanakkale Onsekiz Mart Üniversitesi Ziraat Fakültesi Dergisi, 19(3): 1-7.

Kutinkova, H., Andreev, R., 2004. Integrated pest management in sweet cherry (Prunus avium L.) orchards in Bulgaria. Journal of Fruit and Ornamental Plant Research, 12: 41-47.

Mitko, A.S., Teodora, B.T., Radoslav, A.A., Vilina, D.P., Vasilina, D.M., Teodora, S.S., Nikolina, T.M., Petko, M.M., Dimitar, I.V., 2011. Employing floral baited traps for detection and seasonal monitoring of Tropinota (Epicometis) hirta (Poda) (Coleoptera: Cetoniidae) in Bulgaria. Acta Zoologica Bulgarica, 63(3): 269-276.

Özbek, H., 2008. Türkiye'de 1lıman iklim meyve türlerini ziyaret eden böcek türleri. Uludağ Arıcılık Dergisi, 8(3): 92-103.

Özcan, R., 2007. Başyayla (Karaman) ilçesindeki kiraz ağaçlarında bulunan zararlı böcekler, akarlar ve doğal düşmanlarının tespiti üzerine araştırmalar. Yüksek lisans tezi, Selçuk Üniversitesi, Fen Bilimleri Enstitüsü, Konya.

Öztürk, N., Ulusoy, R., 2003. Mersin ili kayısılarında saptanan zararlılar. Alatarım Dergisi, 2(2): 21-26.

Öztürk, N., Ulusoy, M.R., Erkılıç, L., Bayhan (Ölmez), S., 2004. Malatya ili kayısı bahçelerinde saptanan zararlılar ile avcı türler. Bitki Koruma Bülteni, 44(1-4): 1-13.

Racksko, J., Leite, G.B., Petri, J.L., Zhongfu, S., Wang, Y., Szabo, Z., Soltesz, M., Nyeki, J., 2007. Fruit drop: The role of inner agents and environmental factors in the drop of flowers and fruits. International Journal of Horticultural Science, 13(3): 13-23.

Sağdaş, A., 2011. Farklı tuzakların Afyonkarahisar ili Sultandağı ilçesinde kiraz ve elmalarda zarar yapan baklazınn [Epicometis (=Tropinota) hirta Poda Coleoptera: Scarabaeidae)]'nın yakalanmas1 üzerine etkisi. Yüksek lisans tezi, Süleyman Demirel Üniversitesi, Fen Bilimleri Enstitüsü, Isparta.

Sağdaş, A., Yaşar, B., 2013. Afyonkarahisar ili kiraz bahçelerinde cezbedici karışımı içeren farklı tipteki mavi renkli tuzakların baklazınnı [Tropinota hirta (Poda)] (Coleoptera: Scarabaeidae) erginlerinin yakalanmas1 üzerine etkisi. Süleyman Demirel Üniversitesi Fen Bilimleri Enstitüsü Dergisi, 17(3): 26-31.

Schmera, D., Tóth, M., Subchev, M., Sredkovc, I., Szarukán, I., Jermy, T., Szentesi, A., 2004. Importance of visual and chemical cues in the development of an attractant trap for Epicometis (Tropinota) hirta Poda (Coleoptera: Scarabaeidae). Crop Protection, 23(10): 939-944.

Tezcan, S., Pehlivan, E., 2001. Evaluation of the Lucanoidea and Scarabaeoidea (Coleoptera) fauna of ecological cherry orchards in İzmir and Manisa provinces of Turkey. Ege Üniviversitesi Ziraat Fakültesi Dergisi, 38(2-3): 31-37.

Toth, M., Klein, M.G., Imrei, Z., 2003. Field screening for attractants of scarab (Coleoptera: Scarabaeidae) pests in Hungary. Acta Phytopathologica at Entomologica Hungarica, 38(3-4): 323-331.

Toth, M., Vuts, J., Difranco, F., Tabilio, R., Baric, B., Razov, J., Toshova, T., Subchev, M., Sredkov, L., 2009. Detection and monitoring of Tropinota hirta Poda and Tropinota squalida Scop. with the same trap. Acta Phytopathologica at Entomologica Hungarica, 44(2): 337-344.

Uysal, O., 2011. Farklı tuzakların Isparta ili Yalvaç ilçesinde armut ve eriklerde zarar yapan baklazınnı [Epicometis (=Tropinota) hirta (Poda) (Coleoptera: Scarabaeidae)]'nın yakalanması üzerine etkisi. Yüksek lisans tezi, Süleyman Demirel Üniversitesi, Fen Bilimleri Enstitüsü, Isparta.

Vuts, J., Szarukan, I., Subchev, M., Toshova, T., Toth, M., 2010. Improving the floral Attractant to Lure Epicometis hirta Poda (Coleoptera: Scarabaeidae, Cetoniinae). Journal of Pest Science, 83(1): 15-20.

Yaşar, B., Çeşme, İ., Baydar, M.S., Aysal, İ., Yazır, A.B., 2013. Farklı mavi renkli huni tuzaklarının kiraz ağaçları çiçeklerinde beslenen baklazınnı [Epicometis hirta (Poda) (Coleoptera: Scarabaeidae)]'nın yakalanması üzerine etkisi. Türkiye Entomoloji Bülteni, 3(2): 99-105.

Yaşar, B., Sağdaş, A., 2014. The capturing of the apple blossom beetle, Tropinota hirta (Poda) (Coleoptera: Scarabaeidae): By different traps in Afyonkarahisar. Türkiye Tarımsal Araștırmalar Dergisi, 1(1): 29-34.

Yaşar, B., Uysal, O., 2013. Evaluation of the efficacy of different traps in capturing apple blossom beetle [Tropinota hirta (Poda, 1761)] (Coleoptera: Scarabaeidae). Türkiye Entomoloji Dergisi, 37(2): 169-177. 